\title{
Isolation and identification of pharmaceutically active lipase producing Bacillus spp. from mangrove sediments against Methicillin Resistant Staphylococcus aureus isolated from wound of patients
}

\author{
M.I. Farheena, A. Chithira and A. Mohankumar \\ Division of Microbial Technology, PG and Research Department of Zoology, \\ Chikkanna Govt. Arts College, Tirupur, Tamilnadu, India
}

\begin{abstract}
Ninety two clinical wound samples were collected, among, 50 positive Staphylococcus aureus were isolated. These isolates were characterized morphologically and biochemically. Twenty three antibiotics were used to determine susceptibility patterns by disc diffusion method. The multiple antibiotic resistances (MAR) index were calculated according to the MAR index formula ranged from 0.21 to 0.78. All the 50 isolates of MRSA were showed MAR index in between these ranges. Among these MAR index the pathogenic isolates (100\%) were resistant of Penicillin, while trimethoprim showed resistance (86\%), cephoxitin (80\%), kanamycin (78\%), vancomycin and cepfodoxamine (72\%), moxalactam and quinupristin (70\%), cotrimoxazole (66\%), methicillin (64\%), novobiocin (62\%) and erythromycin (56\%) and there was no resistance found to chloramphenicol, and rifampicin. More than 65\% resistance MRSA isolates were selected for plasmid isolation. Natural products are boundless source for important novel compounds having antagonistic activity against pathogenic organisms. Marine environment covers almost 70\% of the earth surfaces. Organisms present in these environments are extremely rich sources of bioactive compounds. The ocean remains as an unexploited source of many drugs and pharmacologically active substances. Microbial enzymes have many advantages over the animal and plant enzyme, firstly; they are economical and can be produced on large scale within the limited space and time. Secondly, they are capable of producing a wide variety of enzymes; they can grow a wide range of environmental condition. Enzymes have many roles in the pharmaceutical and diagnostic industries. The bacteria Bacillus spp. was isolated from the mangrove sediment, for the lipase production. These enzymes may inhibit the growth of MRSA. Recently with the advent of biotechnology, there has been a growing interest and demand for enzymes with the novel properties.
\end{abstract}

KEY WORDS: PUS, STAPHYLOCOCCUS AUREUS, ANTIBIOTIC SUSCEPTIBILITY TESTING, ANTIMICROBIAL RESISTANCE PLASMID DNA, LIPASE

ARTICLE INFORMATION:

*Corresponding Author: farheena1980@gmail.com Received $21^{\text {st }}$ Oct, 2017

Accepted after revision $27^{\text {th }}$ Dec, 2017

BBRC Print ISSN: 0974-6455

Online ISSN: 2321-4007 CODEN: USA BBRCBA

. Thomson Reuters ISI ESC and Crossref Indexed Journal

NAAS Journal Score 2017: 4.31 Cosmos IF: 4.006

$\odot$ A Society of Science and Nature Publication, 2017. All rights reserved.

Online Contents Available at: http//www.bbrc.in/

DOI: $10.21786 / \mathrm{bbrc} / 10.4 / 17$ 


\section{INTRODUCTION}

Wound infection is one of the major health problems resulting from colonization of wounds by pathogenic organisms Recurrently the predominant Staphylococcus aureus is one of the most important opportunistic pathogen among Staphylococci belonging to Micrococaceae family causing significant infections under appropriate conditions (Prescott et al., 2002). About 20\%-30\% of the general populations are carriers of $S$. aureus. The anterior nasal cavity is the main site of $S$. aureus carriage. Among nasal $S$. aureus carriers, approximately one-half also carry the organism on their skin. Recent studies have established that $S$. aureus is often found at nonnasal sites, particularly the pharynx and the gastrointestinal tract, with some carriers having colonization confined to these sites (Mertz et al., 2009; Acton et al., 2009, Fagbomedo and Femi-Ola, 2017).

Staphylococcus aureus is one of the most versatile nosocomial (i.e. acquired in hospital) and dangerous human pathogen since publication of its role in sepsis by Ogston in 1880 and 1882 (Lowy, 1998). At present, Staphylococcal resistance to antibiotic has been associated with resistant plasmids (R-plasmid) that have the ability to mediate the production of drug inactivated enzymes such as $\beta$-lactamase.The spread of resistance to antimicrobial agents in $S$. aureus is largely due to the acquisition of plasmids and or transposons (Lyon and Skurray, 1987Adeleke and Odelola, 1997; Adeleke et al., 2002 and other functions (King et al., 2006 and Diep et al., 2008).

The un-hygienic hand swab showed presence of MRSA and improvement in hand hygiene, coinciding with a reduction of nosocomial infections and MRSA transmission (Pittet et al., 2000). Treatment options for patients with serious invasive infections caused by methicillinresistant Staphylococcus aureus (MRSA) are limited (Drew, 2007).Increasing resistance of MRSA in recent years has had a significant impact on several aspects of patient care and infection control. Antibiotic policies need to be updated regularly, along with comprehensive monitoring of antibiotic prescribing and antibiotic consumption in healthcare settings. These facts clearly highlight the need of a characterization of MRSA strains at a regular basis at all levels. With the increasing incidence of MDR, recourse to new antibiotics has become necessary.Microbial enzymes have many advantages over the animal and plant enzyme, firstly; they are economical and can be produced on large scale within the limited space and time. Secondly, they are capable of producing a wide variety of enzymes; they can grow a wide range of environmental condition. Enzymes have many roles in the pharmaceutical and diagnostic indus- tries. Therefore the main objective of this study is to isolate lipase enzyme from mangrove sediment bacteria to treat against MRSA isolates.

\section{MATERIAL AND METHODS}

In the present study, 90 pus samples were collected from various Hospitals in and around Tirupur District from November 2012 to February 2013. The samples were processed in the laboratory of PG and Research Department of Zoology, CGAC. First step done was to isolate the organisms from pus samples and then studied the culture susceptibility of Staphylococcus aureus. All pus samples were directly streaked on Mannitol Salt Agar plates and incubated aerobically at $37^{\circ} \mathrm{C}$ for 24 hours. The isolates were identified with standard tests used to identify $S$. aureus such as Gram stain, IMViC, Nitrate reduction, Oxidase, catalase, slide and tube coagulase tests. (Forbes et al., 2007).

Antibiotic sensitivity testing (AST) was done only for confirmed S.aureus strains. Antibiotic sensitivity was performed by Disc Diffusion Method (Bauer et al., 1966). Overnight cultures of S.aureus in nutrient broth were flooded over the surface of Mueller Hinton agar plates. The Mueller Hinton agar plates were allowed to dry before applying antibiotic disc (Baddour et al., 2006). Commercially available antibiotic discs were obtained from (Himedia Labs, Mumbai, India) were gently and firmly placed on the agar plates, which were then left at room temperature for 1 hour to allow diffusion of the antibiotics into the agar medium. The plates were then incubated at $37^{\circ} \mathrm{C}$ for 24 hours. If an antimicrobial activity was present on the plates, it was indicated by an inhibition zone. The diameter of the inhibition zones was measured in millimeter after 24 hours using a standard chart and detected various pattern of antibiotics as sensitive, intermediate and resistant to MRSA.

Multiple drug resistant strains of $S$. aureus which showed 65\% resistance to the antibiotics were selected for plasmid extraction. Isolation of plasmids was performed by Alkaline Lysis Method (Jegadeesh Babu and Rajamanickam, 1998). The plasmids were observed in 0.7\% Agarose gel electrophoresis.Extra cellular enzyme such as lipase was detected from the marine bacteria isolated from mangrove soil sediment. Using plate precipitation test with their specific media screening of lipolytic activity was done by using Rhodamine-B agar plate (Kouker and Jaegar, 1987). The antibacterial activity of the lipase was performed by using well diffusion method. So, hence in view to the significance of mangrove ecosystem which provide a rich source of novel lipase against MRSA isolates. 


\section{RESULTS AND DISCUSSION}

Among the 92 clinical pus sample (Plate: 1) isolates of S. aureus, 50 positive Staphylococcus aureus (Plate: 2) were identified as methicillin resistant Staphylococcus aureus (MRSA) by disc diffusion method (Plate: 3). Electrophoretic analysis of the plasmid DNA prepared was carried out by agarose gel electrophoresis on $0.7 \%$. Five MRSA isolates (FA21, FA24, FA48, FA49 and FA50) which was showed more than 65\% resistance against tested antibiotics were selected for plasmid isolation (Plate: 4).Strain no FA49 harbored a single plasmid DNA on basis of electrophoretic mobility on agarose gel. Other four strains (FA21, FA42, FA48 and FA50) harbored a double plasmid DNA. The molecular size of the plasmid DNA was calculated to be $1500 \mathrm{bp}$ and 1000bp respectively. 100bp DNA ladder (Medox biotech, Chennai) was used as marker DNA.
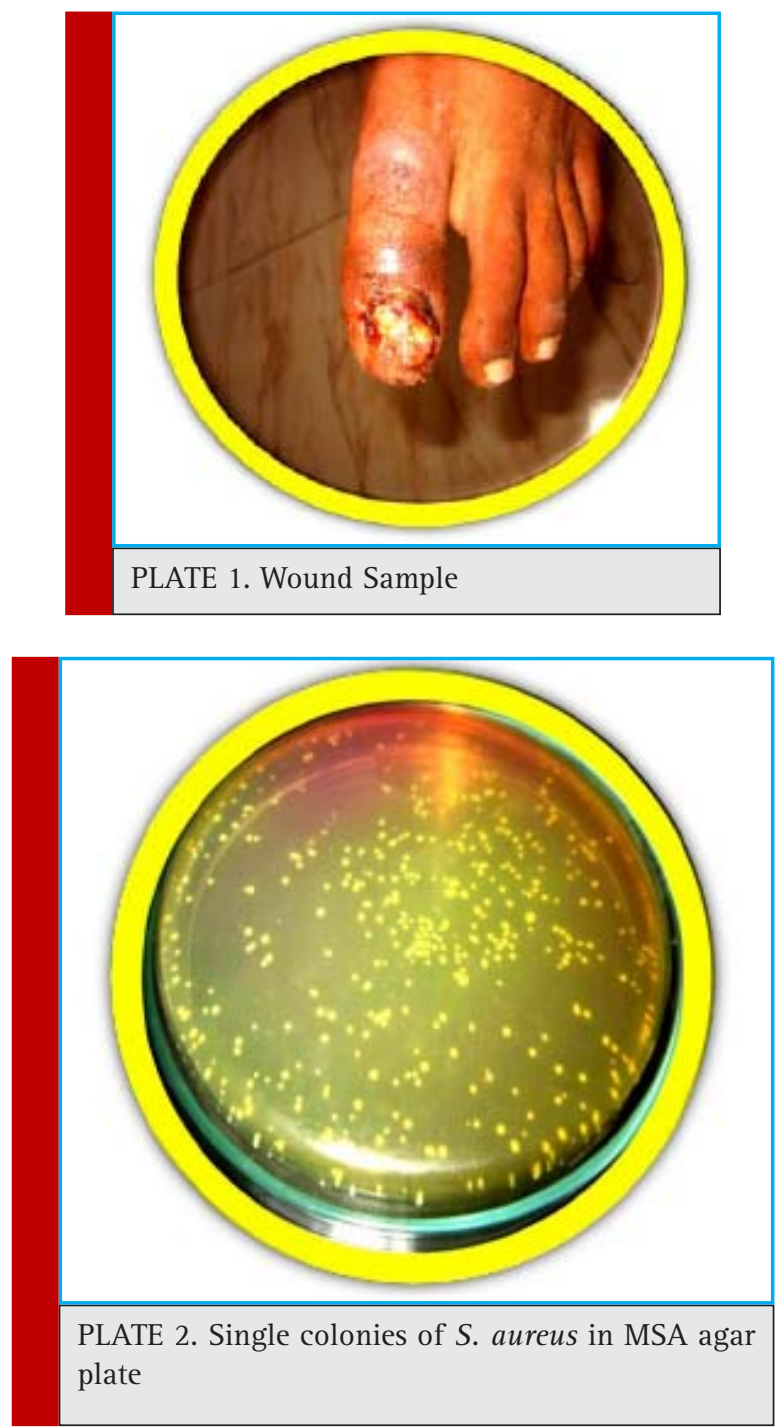

Marine bacterium Bacillus spp. was isolated from marine sediment collected from Pitchavaram mangrove. This bacterium was identified by biochemical characters. This bacterium was identified by using ZoBell medi a and lipase activity screening by Rhodamine B agar media (Plate: 5) followed by the antimicrobial activity of lipase enzyme was done by well diffusion assay (Plate: 6).

In Rhodamine B agar the isolates Bacillus spp. showed halos around the bacterial colonies under ultra violet irradiation. Kouker and Jaeger (1987) detected a plate assay for microbial lipase in a medium containing triacylglycerol with addition of fluorescent dye rhodamine B. Substrate hydrolyses causes the formation of orange fluorescence halos around bacterial colonies visible upon UV irradiation. The isolated strains were screened for lipase production.

Staphylococcus aureus is recognized as an important bacterial pathogen contributing towards hospital infection, globally. Despite the use of potent antibiotic still high mortality exist in case of Staphylococcus aureus infection. In the present study, antibiotic susceptibility pattern was assessed for Gram-positive cocci from pus and a high resistance was recorded against antibiotics tested. Despite the numerous studies found that advent of antibiotics, it was though that warrant for the treatment of the $S$. aureus related infection got issued but due to the development of antibiotic resistant gene in the plasmid of $S$. aureus could depend itself in a much secured manner. So, these facts clearly highlight the need of a characterization of MRSA strains at a regular basis at all levels. With the increasing incidence of MDR, recourse to new antibiotics has become necessary. In recent year the microbial enzymes have many roles in the pharmaceutical and diagnostic industries. Therefore the main objective of this study is to isolate lipase enzyme from mangrove sediment bacteria to treat against MRSA isolates.

Adame et al (2010) collected 250 samples from healthy humans, cattle, sheep and goats for the isolation of $S$. aureus and they reported that the antimicrobial susceptibility test showed highly susceptible to Ciproxcin (91.1\%), Norfloxacin (90.2\%), Rifampicin (73.2\%), Streptomycin (72.3\%), Erythromycin (71.4\%), Norbactin (64.3\%), but the isolates showed resistant to Ceftazimide (7.1\%), Cefotaxime (14.3\%), and Ampiclox (31.3\%). Totally 92 wound samples were collected from infected human, among 50 S. aureus were isolated, Penicillin showed 100\% resistant against the isolates, Amikacin and tetracycline showed 6\% and 4\% resistance respectively in the present study.

Susmita Bhattacharya et al (2013) have isolated 280 MRSA strains from 714 Staphylococcus aureus of various clinical samples. Among 280 MRSA, 21 strains were 


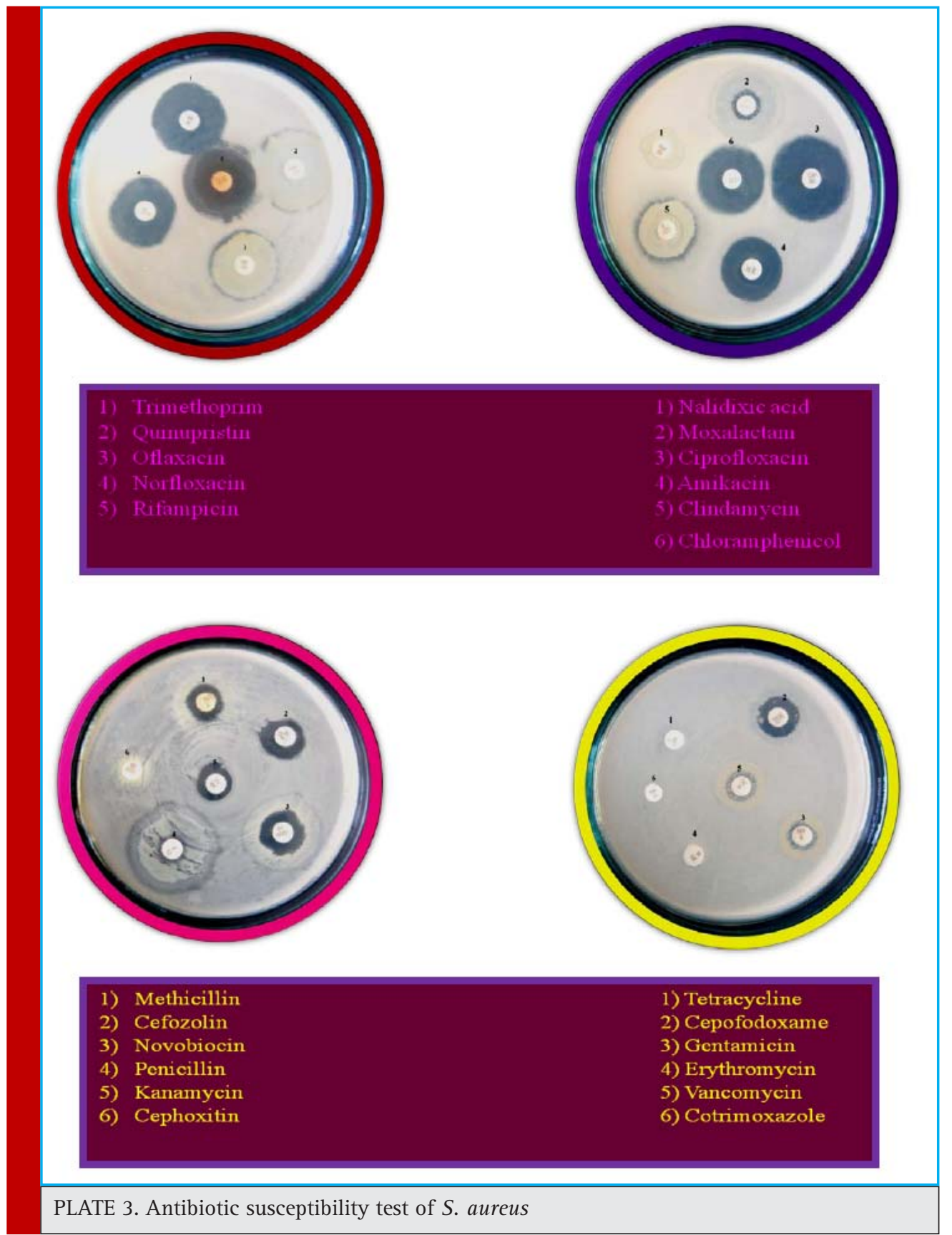

found to be resistant to Vancomycin by disc diffusion test. Similar method was used in the present investigation for antimicrobial susceptibility test. Among 50 MRSA strains, 36 strains were found to be resistant to Vancomycin.High rates of resistance to Penicillin among S.aureus have been observed since 1959, when this frequency was recorded at $80 \%$ which have been extended to amoxicillin and to ampicillin. Giarola et al (2012) observed that the 90\% resistance to Penicillin, $14 \%$ to rifampicin and 59\% to azithromycin. Similarly high rates of resistance was observed against Penicillin $(100 \%)$ but none of the isolates showed resistance against rifampicin in this study.

All the isolates of S.aureus were multidrug resistant and one isolate was pane resistant for all the tested drugs. $50 \%$ resistance was observed in penicillin, methicillin, polymyxin - B and Chloramphenicol 95.5\%, 77.3\%, $68.2 \%$ and 51.5\% respectively (Alebachew et al 2009). Similarly Penicillin and methicillin showed 100\% and $64 \%$ resistance respectively, whereas none of the isolates 


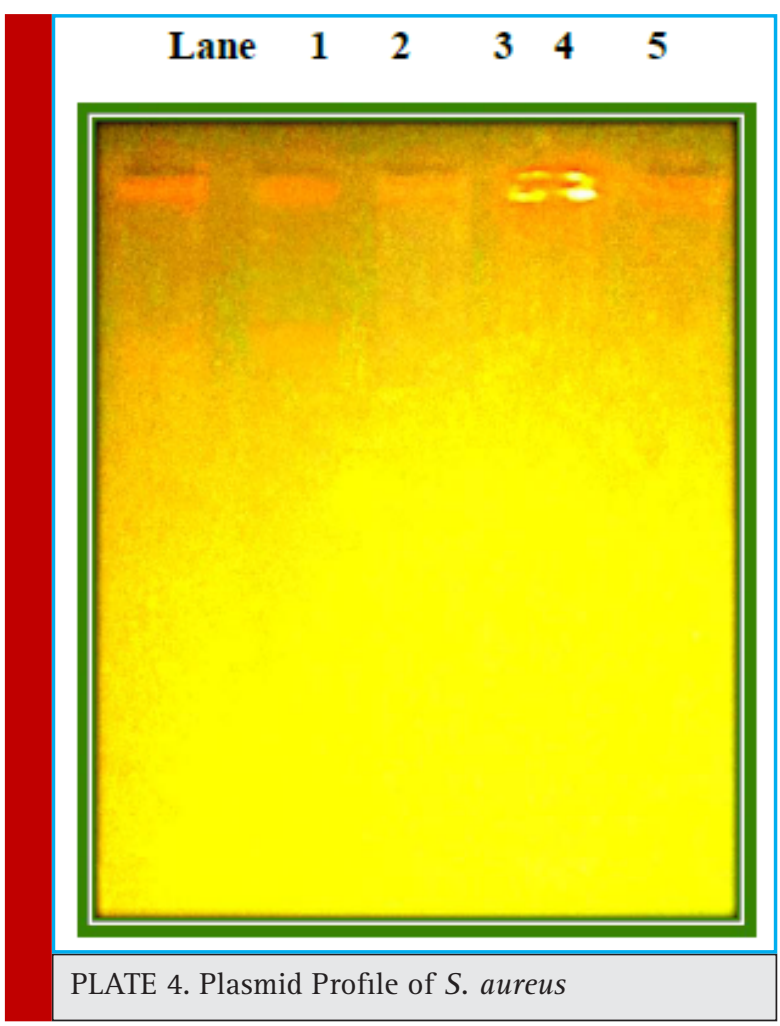

showed resistance against chloramphenicol. Totally 23 antibiotic drugs were tested, among 23 antibiotics, 12 antibiotics were showed were than 50\% resistance.

Twenty four Staphylococcus aureus isolates were tested invitro to determine their antibiotic susceptibility patterns by antibiotic disc diffusion method. All the isolates showed multiple antibiotic resistances to the antibiotics tested. All the isolates were 100\% resistant to Ampicillin, Amoxicillin Nalidixic acid (87.5\%), Cef-

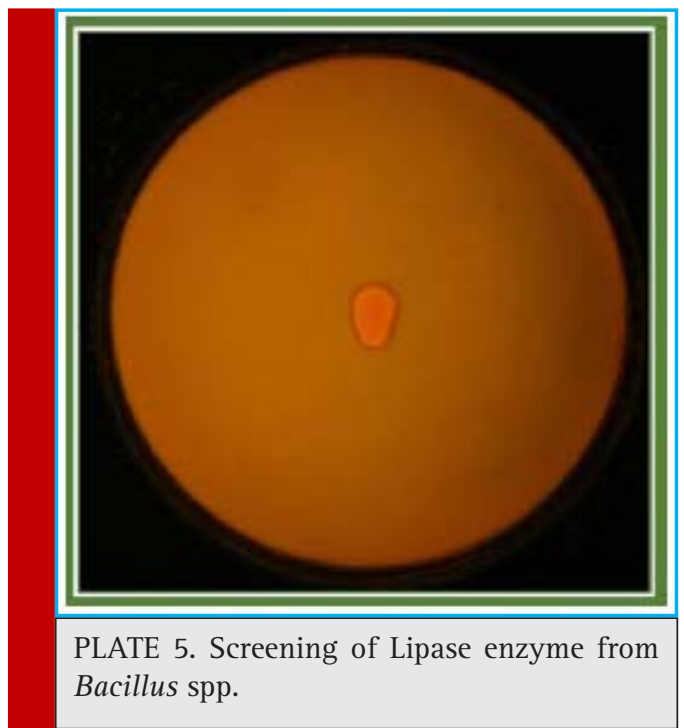

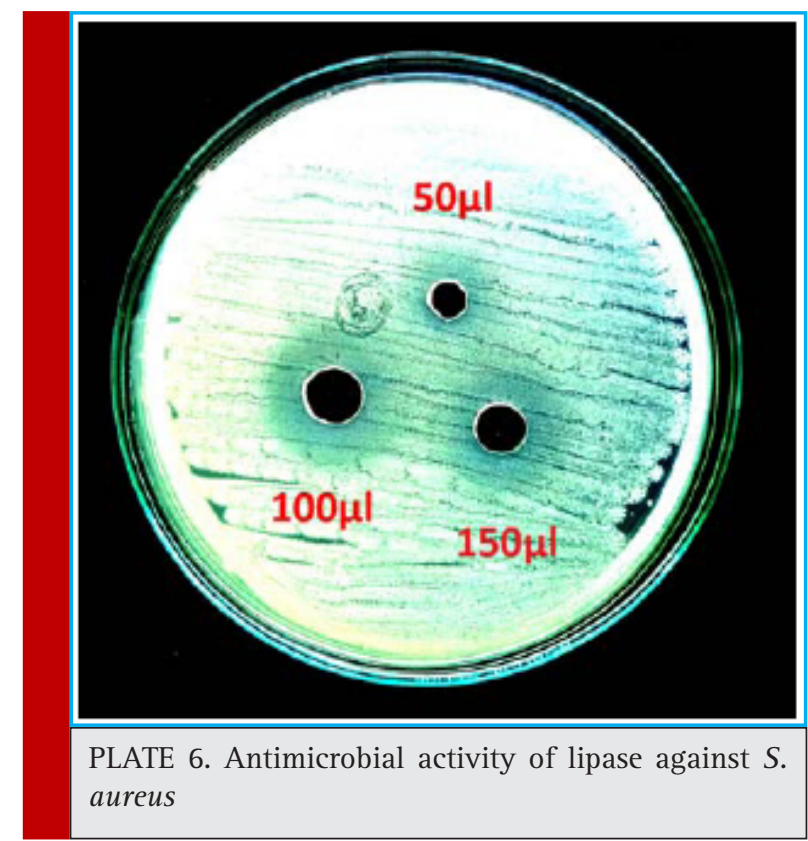

triaxone (75\%), Streptomycin (54.16\%), Erythromycin, tetracycline, Kanamycin and Neomycin (25\%), Oxacillin (41.6\%), Tobramycin and there was no resistance found to Chloramphenicol, Vancomycin, Norfloxacin, Ciprofloxacin and Rifampicin (AI-Hamdani and Hamad, 2012). Totally 50 Staphylococcus aureus isolates were tested invitro by similar method. Here also all the isolates were showed multiple antibiotic resistance to the drugs tested. But Chloramphenicol and Rifampicin were showed 100\% resistant.

Udo and Sarlchoo (2010) have characterized four MRSA isolates, during plasmid analysis, four isolates had showed three plasmid patterns, Isolate K6482 contained two plasmids ( 28 and $26 \mathrm{~Kb}$ ), K6531 and K6533 each contained three plasmids $(28,21$ and41 $\mathrm{Kb})$ and K6552 contained two plasmids ( 41 and $41 \mathrm{~Kb}$ ). In this present study five strains which showed more than 65\% resistance against all drug tested were taken for plasmid isolation, Isolate FA49 contained one plasmid $(1.5 \mathrm{~Kb})$ and the isolates FA21, FA24, FA48 and FA50 each contained two plasmids $(1.5 \mathrm{~kb}$ and $1 \mathrm{~Kb})$.Herari et al (2008) studied that the lipase production in an indigenous lipolytic Bacillus spp. in media containing tributyrin, tween 80 and rhodomine B- Olive oil. The statistical model was used to predict the optimum experimental conditions for bacterial growth and lipase production. Similarly in the present study Bacillus spp. was used for lipase production, it was isolated from the sediment of Pichavaram mangrove, lipase production was confirmed by Rhodomine B-olive oil plate.Mohankumar and Tamilselvi (2012) have isolated marine bacteria includes Bacillus spp. Pseudomonas spp. Staphylococcus spp. and Vibrio spp. for lipase production. Amount of lipase was 
estimated by plate assay method and titration. Similar method was followed in the present study that the Bacillus spp. was isolated from mangrove sediment samples and the lipase production was estimated only by plate assay method.

\section{CONCLUSION}

The present study has indicated that MRSA strains were found to be develop resistance day by day to the currently used antibiotics. This situation needs some novel therapeutic drugs from marine environment for an alternative therapy for treatment of wound causing MRSA isolates.

\section{REFERENCES}

A1- Hamdaniand, A., Hamad G. (2012). Study of plasmid profile, susceptibility patterns of clinical Staphylococcus aureus isolated from patients with otitis media in Basrah. Journal of Basrah Researches (Sciences), 38 (1): 79-89.

Acton, D.S., Tempelmans Plat Sinnige M.J, Van Wamel W, De Groot N,Van Belkum A. (2009). Intestinal carriage of Staphylococcus aureus: how does its frequency compare with that of nasal carriage and what is its clinical impact. Eur J Clin Microbiol Infect Dis. 28: 115 - 127.

Adamu, J.Y., Raufu A.I, Chimaroke F.C, Ameh J.A. (2010). Antimicrobial susceptibility testing of Staphylococcus aureus isolated from apparently healthy humans and animals in Maiduguri, Nigeria. International Journal of Biomedical and Health Sciences, 6 (4): 191-195.

Adeleke, O.E., Odelola H.A, Oluwole F.A. (2002). Curing of antibiotic resistance in clinical strains of Staphylococcus aureus. Afr J Med Pharm Sci. 6: 19-25.

Adeleke, O.E., Odelola H.A. (1997). Plasmid profiles of multiple drug resistant local strains of Staphylococcus aureus. Afr J Med Pharm Sci. 26: 119-121.

Alebachew, Gizachew Yismaw, Ayelegn Derabe, Zufan Sisay. (2012). Staphylococcus aureus burn wound infection among patients attending yekatit 12 hospital burn unit, ADDIS ABABA, Ethiopia. Ethiop. J. Health. Sci, 22 (3) 209-213.

Baddour, M.M., Abuelkheir M.M., Fatani J.A. (2006). Trends in antibiotic susceptibility patterns and epidemiology of MRSA isolates from several hospitals in Riyadh, Saudi Arabia. Annals of Clinical Microbiology and Antimicrobials, 5(30): 1- 11.

Bauer, A.W., Kirby W.M., Sherris J.C., Truck M. (1996). Antibiotic susceptibility testing by a standardized single disk method. Am.J.Clin. Pathol., 45 (4): 493- 496.

Diep, B.A., Chambers H.F., Graber C.J, Szumewski J.D, Miller L.G, Han L.L , Chen J.H, Lin F. (2008). Emergence of multidrug resistant Staphylococcus aureus clone USA 300 in man who have sex with men. Ann Intern Med.148: 1-17.
Drew, R.H. (2007). Emerging options for treatment of invasive multidrug resistant Staphylococcus aureus infections Pharmacotherapy, 27: 227-49.

Edet Udo, E., Eiman Sarkhoo.(2010). Genetic analysis of high level mupirocin resistance in the ST80 clone of community associated methicillin resistant Staphylococcus aureus. Journal of Medical Microbiology, 59: 193-199.

Fagbomedol J and Femi-Ola, T.0 (2017). Incidence of wound infections and the prevelance of multi drug resistant Staphylococcus aureus in Nigerian hospital. Academia Journal of Scientific Research. 5(9): 316-322.

Giarola, Rosiane Ribeiro dos Santos, Maria Cristina Bronharo Tognim, Sueli Donizete Borelli, Joao Bedendo. (2012). Carriage frequency, phenotypic and Genotypic characteristics of Staphylocoous aureus isolated from dialysis and kidney transplant patients at a hospital in Northern Parana. Brazilian journal of Microbiology, 923-930.

Herari, K., Eftekhar F, Yakhchali B, Tabendeh F. (2008). Isolation and identification of lipase producing Bacillus spp from soil. Pak. J. Bio. Sci, 11: 740-745.

King, M.D., Humphrey B.J, Wang Y.F. (2006). Kourbalova EV, Ray SM , Blumbrg HM; Emergence of community acquired methicillin resistant Staphylococcus aureus USA 300 clone as the predominant cause of skin and soft tissue infections. Ann Intern Med. 144: 309-317.

Kouker, G., Jaeger K.E. (1987). Specific and sensitive plate assay for bacterial lipases. App.Environ. Microbiol. 53: 211213.

Lowey, F.D. (1998). Staphylococcus aureus infections. New Eng J Med. 339: 520- 532.

Lyon, B.R, Skurray R. (1987). Antimicrobial resistance of Staphylococcus aureus: genetic basis. Micr Rev. 51: 88-134.

Mertz, D., Frei R, Periat N. (2009). Exclusive Staphylococcus aureus throat carriage: at risk populations. Arch Intern Med. 69: 172-178.

Mohankumar, A., Tamilselvi S. (2012). Antibiotic pattern of methicillin resistant Staphylococcus aureus is chronic wound of isolated from chronic wound of fisherman community. International Journal of Microbiological Research, 3 (2): 109116.

Pittet, D.S., Hugonnet S.H, Mourouga P, Touveneau S, Perneger T.V. (2000). Effectiveness of hospital wide programme to improve compliance with hand hygiene. The Lancet, 356: 1307-1312.

Prescott, L.M., Harely J.P, Klein D.A. (2002). Microbiology $5^{\text {th }}$ McGraw Hill Comp. USA.

Susmita Bhattachrya, Kuhu Pal, Mitali Chatterjee, Mandira Banerjee, Pratip Kumar Kundu, Swapan Kumar Niyogi. (2013). Vancomycin intermediate Staphylococcus aureus isolated from a tertiary care hospital in Kolkata. IOSR Journal of Dental and Medical Sciences, 5 (2): 19-23. 